\title{
The Identification of Acute Post Streptococcus Glomerulonephritis Risk Factors in Children
}

\author{
Suhardi $^{1}$, Husein Albar $^{2}$, Syarifuddin Rauf ${ }^{3}$, Dasril Daud ${ }^{4}$ \\ ${ }^{1}$ Senior resident, Nephrology Division, Department of Pediatrics, Medical Faculty, Hasanuddin University, Makassar, Indonesia \\ ${ }^{2}$ Supervisor, Nephrology Division, Department of Pediatrics, Medical Faculty, Hasanuddin University, Makassar, Indonesia \\ ${ }^{3}$ Supervisor, Nephrology Division, Department of Pediatrics, Medical Faculty, Hasanuddin University, Makassar, Indonesia
}

${ }^{4}$ Supervisor, Hematology \& Oncology Division, Department of Pediatrics, Medical Faculty, Hasanuddin University, Makassar, Indonesia

\begin{abstract}
Introduction: Acute Post Streptococcal Glomerulonephritis (APSGN) is one of the most common cause of glomerular disease in children in developing countries, including Indonesia. Therefore, it is important to know the various risk factors that affect the incidence of APSGN, so the early diagnosis can be established. Materials and methods: A cross-sectional study was conducted to identify the risk factors of APSGN in children. The data were collected from medical records of APSGN patients hospitalized in Dr. Wahidin Sudirohusodo Hospital, Makassar from January 2010 to December 2014. Results: There are 137 samples consisted of 86 (62.8\%) APSGN cases and 51 (37.2\%) of Non-APSGN cases. The bivariate analyses revealed that there were 5 variables that associated to APSGN: age $\geq 5$ years (p=0.000; COR 35,42 with 95\% CI (4.51-278.27)), malnutrition (p=0.000; COR 6.77 with 95\% CI (3.14 14.61)), low socioeconomic status $(p=0.000$, COR 17.94 with 95\% CI $(7.45-43.21))$, less maternal's education level $(p=0.000 ; C O R$ 18.95 with 95\% CI (7.63 - 47.11)) and the rainy season $(p=0.003$; COR 2.91 with 95\% CI (1.41 - 5.99$))$. The multivariate analyses revealed that there were 4 variables associated with $A P S G N$ : age $\geq 5$ years $(p=0.019 ; A O R=14.36)$, low socioeconomic status $(p=0,005$; AOR 5.25), less maternal's education level ( $p=0.004 ;$ AOR $=5.54)$ and rainy season $(p=0.03 ;$ AOR $=3.05)$. Conclusions: The risk factors of APSGN in children were: age $\geq 5$ years, low socioeconomic status, less maternal's education level and rainy season.
\end{abstract}

Keywords: Acute Post Streptococcus Glomerulonephritis, risk factor, children

\section{Introduction}

Glomerulonephritis is a general term used to describe a wide range of kidney disease who experienced proliferation and inflammation in glomerulus due to an immunological process. ${ }^{[1]}$ Acute glomerulonephritis (AGN) is a one form of glomerulonephritis characterized by a sudden decline in glomerular filtration rate with clinical manifestations such as edema, hematuria, hypertension, oliguria and kidney insufficiency. Therefore, AGN often referred as acute nephritic syndrome (ANS). ${ }^{[2]}$

Acute glomerulonephritis is most common in children after bacterial infection is Streptococcus group A $\beta$-hemolyticus (SBHA), namely acute post-streptococcal glomerulonephritis (APSGN). It is estimated that more than 470,000 cases occur annually APSGN worldwide, about $97 \%$ occur in developing countries and almost 5000 cases were fatal. $^{[3,4]}$ In Indonesia, a study in 2005 reported the type of AGN in children most is APSGN which is evident from the increase in titer of anti - streptolisin O (ASO) as much as $66.6 \%$ of cases and decreased the concentrations of

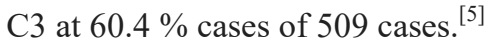

Acute post-streptococcal glomerulonephritis is an immunemediated disease associated with acute respiratory tract infections and skin infections by a bacteria strains of SBHA nephritogenic. ${ }^{[6]}$ If the host is vulnerable to infection, the body will provide a response to streptococcal antigens by forming antibodies. Ag-Ab complex is formed in blood and it is referred to as a soluble antigen-antibody complex (SAAC). SAAC then circulated in the circulation, causing the complement system (which is activated by plasmin because of streptokinase) participated react; therefore, the complement C3 will unite with SAAC circulates in the glomerulus, where the complex is mechanically trapped in the basement membrane and form deposits under Bowman's capsule epithelium, Deposit complex Ag-Ab-C3 (humps) subsequently resulting in lesions and inflammation that will attract polymorphonuclear leukocytes (PMN) and monocytes leading to the lesion. Through the process of chemotaxis, phagocytosis and release of enzymes lisozom and last endothelial and glomerular basement membrane will be damaged underlying clinical manifestations in APSGN. ${ }^{[7]}$

It is still cannot be explained why there is only $10-15 \%$ of APSGN patients infected with the SBHA nephritogenic strain bacteria. This is probably due to the host factors specified and environmental factors that contribute to exposure the germs and immunologic responses underlying in APSGN patients. APSGN attack all age groups where the age group 5-15 years (in Indonesia between the ages 2.5 to 15 years with a peak age of 8.4 years) are the age group most common and least common in infants. The male suffered two times more often than female. APSGN more common in the tropics and usually affects the children from lower economic groups. In Indonesia, $68.9 \%$ came from low socioeconomic families and $82 \%$ of low-educated families. ${ }^{[5]}$ APSGN genesis also allegedly associated with the season. Genetic factors also play a role, it is seems from the incidence of index cases in siblings $(38 \%)$ higher than the risk of an epidemic of children (4-28\%). The influence of genetic aspects supported by a strong research report on the relationship between APSGN with HLA-DRW4 and HLA-DR1 most frequently attacked by APSGN. ${ }^{[7,8]}$

The clinical manifestations are varied often causes the difficulty to diagnose this disease at early stage so that the 


\section{International Journal of Science and Research (IJSR) \\ ISSN (Online): 2319-7064 \\ Index Copernicus Value (2013): 6.14 | Impact Factor (2014): 5.611}

patient with delayed treatment led to complications and death. The study by Kumar found that edema, proteinuria, and hematuria is the most clinical symptom. ${ }^{[9]}$ Anasarca edema is the most common symptom and it can reach the two-thirds of all patients. Respiratory distress and pulmonary edema have been reported as a symptom that appears on APSGN although it is not accompanied by abnormalities in the urine. ${ }^{[10]} \mathrm{CY}$ Chiu et al. reported there are six patients exhibiting respiratory distress, initially diagnosed as pneumonia, two of these patients eventually develop respiratory failure due to the late diagnosis. ${ }^{[11]}$ In a study of 152 APSGN patients, Bircan Z et al. found there are $44(28.9 \%)$ patients had pulmonary edema but they referred from a local hospital with the diagnosis of broncopneumonia and heart failure. ${ }^{[12]}$

APSGN is one of the main causes of the end stage kidney failure and high rates of morbidity and mortality in patients when their diagnosed and treatment are late. Death usually occurs in the acute phase due to acute kidney failure, acute pulmonary edema or hypertensive encephalopathy. ${ }^{[13]}$

The purpose of this study was to identify the risk factors for APSGN in children's and it is not been done in Indonesia yet.

\section{Materials and Methods}

This study is a retrospective study with cross sectional study approach and case control (based on the type of data/ problem) to determine the incidence and to identify the risk factors associated with the incidence of APSGN in children. We conducted this study at Dr. Wahidin Sudirohusodo Hospital in Makassar, starting from February until May 2015 using a data from medical records of APSGN patients registered in children Medical Staff Functional (MSF) of Dr. Wahidin Sudirohusodo Hospital from January 2010 until December 2014.

The sample was eligible populations of the AGN patients (APSGN and ANS of Non APSGN) who met the study inclusion and exclusion criteria. The protocol was conducted in accordance with principles of good clinical practice, including obtaining written informed consent from each participant's parent, and was approved by the human studies committees applicable to each study site. Patients who met the criteria are grouped into the groups of APSGN and non APSGN, then we recorded the data related to the study such as the patient initials, registration number, age at diagnosis, sex, nutritional status, socioeconomic status, maternal education level and the season (rainy and dry season). Likewise, the results of clinical examinations and investigations that support the diagnosis of APSGN and non APSGN in children. The data was analyzed with the appropriate statistical methods, namely the analyses of univariate, bivariate, and multivariate.

\section{Result}

Table 1 shows the characteristics of the study sample were assessed in the form of sex, age, nutritional status, socioeconomic status, maternal's education level and the pattern of the season. From the total of sample, 137 patients were treated with APSGN and ANS of non APSGN, obtained male $(64.2 \%)$ more than female $(35.8 \%)$ with a ratio of 1.79: 1 . The patient's age are varied from 1.75 years to 15.5 years with a mean of 9.4 years. From the results obtained the patient data processed with under nutritional status $(59.1 \%)$ more than well nutritional status (40.9), low socioeconomic status is $58.4 \%$ and the high socioeconomic status (41.6), low maternal education level (54.7\%) more than the high maternal education level $(45.3 \%)$ and they are suffers more in the rainy season $(62.8 \%)$ than in the dry season $(37.2 \%)$.

Table 1: Study Characteristics

\begin{tabular}{|c|c|c|}
\hline No. & Characteristics Sample & Total (N:137) \\
\hline \multicolumn{3}{|c|}{ 1. $\operatorname{Sex}(\%)$} \\
\hline & $\mathrm{M}: \mathrm{F}$ & $88: 49(64.2: 35.8)$ \\
\hline \multirow[t]{3}{*}{2.} & Age (years) & \\
\hline & Range & 1.75 to 15.5 \\
\hline & Mean & 9.4 \\
\hline & Nutritional status (\%) & \\
\hline & Well nutrition & $56(40.9)$ \\
\hline & Under nutrition & $81(59.1)$ \\
\hline \multirow[t]{3}{*}{4.} & Socio-Economic Status ( $\%$ ) & \\
\hline & High & $57(41.6)$ \\
\hline & Low & $80(58.4)$ \\
\hline & Matemal's education level (\%) & \\
\hline & High/Medium & $62(45.3)$ \\
\hline & Low & $75(54.7)$ \\
\hline \multirow[t]{3}{*}{6.} & Season Pattern (\%) & \\
\hline & Dry & $51(37.2)$ \\
\hline & Rainy & $86(62.8)$ \\
\hline
\end{tabular}

Table 2 shows the characteristics of the APSGN and ANS of non APSGN group. Of the 137 subjects study showed patients APSGN is 86 children $(62.8 \%)$ and patients with ANS of non APSGN is 51 children (37.2\%). It turns out that the male suffered APSGN (60.5\%) more than a female of non APSGN (70.6\%). Of the 86 APSGN patients, 85 $(98.8 \%)$ of children aged $\geq 5$ years and $1.2 \%$ under the age of 5 years. The youngest APSGN patient is age 4 years and 3 months and the oldest one is 15 years and 6 months. The APSGN patients with under nutrition status (75.6\%) more than the well nutritional status $(24.4 \%)$, low socioeconomic status is $81.4 \%$ and the high socioeconomic status is $18.6 \%$, the low maternal education levels is $77.9 \%$ more than the high maternal education level with only $22.1 \%$, and they are suffering this diseases in the rainy season $(72.1 \%)$ more than in the dry season $(27.9 \%)$. 


\section{International Journal of Science and Research (IJSR) \\ ISSN (Online): 2319-7064 \\ Index Copernicus Value (2013): 6.14 | Impact Factor (2014): 5.611}

Table 2: The characteristics of APSGN and ANS of non APSGN groups

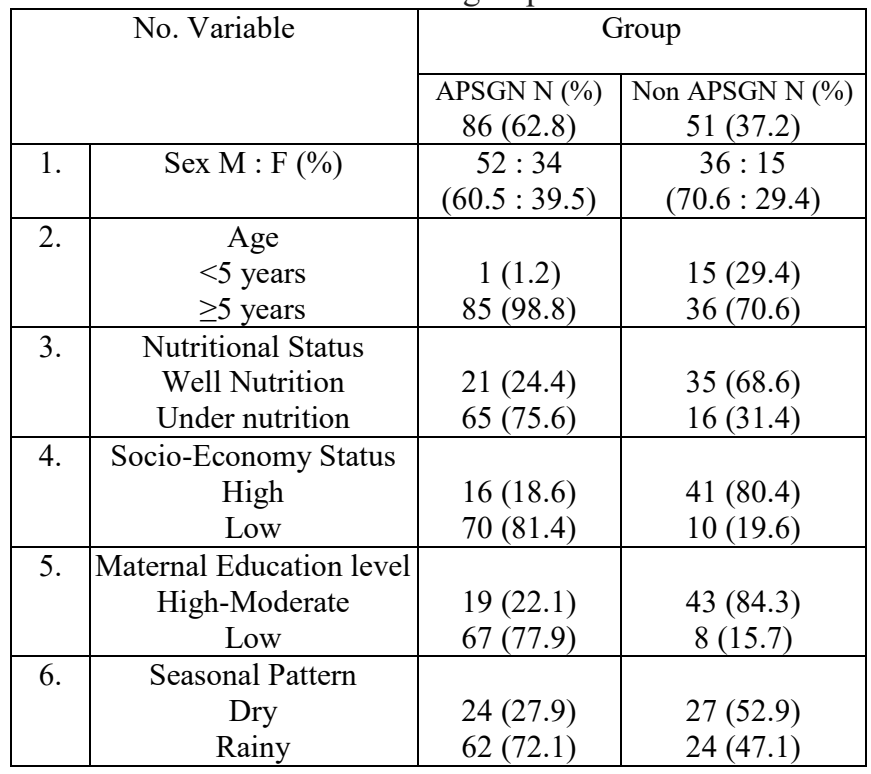

Bivariate test against APSGN incidence of the risk factors has been studied, it was found that only 5 significant variables such as age $(\mathrm{p}=0.000$; COR 35.42 with a $95 \%$ CI (4.51 to 278.27)), nutritional status $(\mathrm{p}=0.000 ; \mathrm{COR}=6.77$ with $95 \%$ CI (3.14 to 14.61$)$ ), socioeconomic status ( $p=$
$0.000 ; \mathrm{COR}=17.94$ with a $95 \%$ CI $(7.45$ to 43.21$))$ maternal education level $(\mathrm{p}=0.000 ; \mathrm{COR}=18.95$ with a $95 \%$ CI $(7.63$ to 47.11$))$ and seasonal patterns $(p=0.003$; $\mathrm{COR}=2.91$ with $95 \% \mathrm{CI}(1.41$ to 5.99$)$ while the sex variable (Table 3 ) was not statistically significant with $\mathrm{p}=$ $0.232(\mathrm{p}>0.05)$.

Table 3: Relationship of sex and the APSGN incidence in children

\begin{tabular}{|c|c|c|c|}
\hline \multirow{2}{*}{ Sex } & \multicolumn{2}{|c|}{ Group } & \multirow{2}{*}{ Total } \\
\cline { 2 - 3 } & APSGN & Non APSGN & \\
\hline Male & $52(59.1 \%)$ & $36(40.9 \%)$ & $88(100 \%)$ \\
Female & $34(69.4 \%)$ & $15(30.6 \%)$ & $49(100 \%)$ \\
\hline Total & $86(62.8 \%)$ & $51(37.2 \%)$ & $137(100 \%)$ \\
\hline \multicolumn{3}{|c|}{ Chi- square $\mathrm{X}^{2}=1.428 \mathrm{df}=1 \mathrm{p}=0.232$} \\
\hline
\end{tabular}

After the multivariate analyses with multiple logistic regression analyses (Table 4) of the variables that have a relationship with the incidence in APSGN children obtained only four significant variables, that is age (AOR 14.36 with a $95 \%$ CI $(1.56$ to 132.58$)$ ), socioeconomic status (AOR 5.25 with $95 \%$ CI (1.66 -16.58)), maternal education level (AOR 5.54 with $95 \%$ CI $(1.75$ to 17.59$)$ ) and the season pattern (AOR 3.05 with 95\% CI (1.11 to 8.37)) while the nutritional status variable was not statistically significant (AOR 1.24 with 95\% CI (0.42- 3.63).

Table 4: The results of multiple logistic regression analyses of the risk factors for APSGN children

\begin{tabular}{|l|l|c|c|c|c|c|}
\hline No & \multicolumn{1}{|c|}{ Variable } & B & S.E & df & AOR & $95 \%$ CI \\
\hline 1. & Age (A) & 2.665 & 1.134 & 1 & 14.36 & $1.56-132.58$ \\
\cline { 2 - 7 } 2. & Social Economy (SE) & 1.658 & 0.587 & 1 & 5.25 & $1.66-16.58$ \\
\cline { 2 - 7 } 3. & Maternal Education (I) & 1.713 & 0.589 & 1 & 5.54 & $1.75-17.59$ \\
\cline { 2 - 7 } 4. & Seasonal Pattern (S) & 1.115 & 0.515 & 1 & 3.05 & $1.11-8.37$ \\
5. & Nutritional Status (N) & 0.211 & 0.550 & 1 & 1.24 & $0.42-3.63$ \\
& Constanta (a) & -11.282 & 2.558 & & 0.00 & - \\
\hline
\end{tabular}

Tabel 5: Probability of the APSGN based on the existing risk factor

\begin{tabular}{|l|c|}
\hline \multicolumn{1}{|c|}{ Risk Factor } & Probability GNAPS (\%) \\
\hline No. Risk Factor & $1.58 \%$ \\
\hline 1 (rainy season) & $4.66 \%$ \\
\hline 1 (Age $\geq 5$ years) & $18.74 \%$ \\
\hline 2 (Rainy season + Less maternal education) & $21.35 \%$ \\
\hline 2 (Low Social Economy Status + Less maternal education) & $31.84 \%$ \\
\hline 2 (Age $\geq 5$ years + Rainy Season) & $41.28 \%$ \\
\hline 2 (Age $\geq 5$ years + Low Social Economy Status) & $54.76 \%$ \\
\hline 2 (Age $\geq 5$ years + Less maternal education) & $56.11 \%$ \\
3 (Age + Social Economy Status + Rainy Season) & $78.68 \%$ \\
3 (Age + maternal education level + Rainy Season) & $79.58 \%$ \\
3 (Age + Social Economy Status + maternal education level) & $87.03 \%$ \\
4 (Age + Social Economy Status + maternal education level + Season) & $95.34 \%$ \\
\hline
\end{tabular}

Based on the results of multiple logistic regression analyses with the confidence interval (CI) of $95 \%$ for each risk factor of APSGN above, then the probability of APSGN obtained in a child treated with ANS is based on these risk factors (Table 5).

\section{Discussion}

This study shows there are 5 risk factors for APSGN occurs in children treated with ANS ie $\geq 5$ years of age, under nutritional status, low socioeconomic status, less of maternal education level and the rainy season. However, after the multivariate analyses, only four variables were significant as the independent rsisk factors for APSGN incidence in children such as aged $\geq 5$ years (AOR 14.36 with a $95 \% \mathrm{CI}$ (1.56 to 132.58)), low socioeconomic status (AOR 5.25 with $95 \%$ CI (1.66 to 16.58)), less of maternal education level (AOR 5.54 with $95 \%$ CI $(1.75$ to 17.59$)$ ) and the rainy season (AOR 3, 05 with a 95\% CI (1.11 to 8.36)).

In this study it was found that most forms of $A G N$ is APSGN that is equal to $62.8 \%$ of the 137 cases existing the 


\section{International Journal of Science and Research (IJSR) \\ ISSN (Online): 2319-7064 \\ Index Copernicus Value (2013): 6.14 | Impact Factor (2014): 5.611}

AGN. The results are almost same as the obtained result in a previous study on the profile of AGN in Indonesian children who get an increase in ASO titer in $66.6 \%$ of cases. ${ }^{[5]}$ Higher yields obtained in South Iran by Derakhshan, who received $122(89 \%)$ cases of 137 children APSGN by AGN. ${ }^{[14]}$ Similarly, other studies in Iran by Sepahi et al. which gained $87(92.5 \%)$ APSGN cases of 94 AGN cases. ${ }^{[15]}$

Based on the bivariate analyses, the relationship of APSGN incidence in children by sex showed there is no significant difference with $p=0.232(p>0.05)$. However, in this study obtained from 86 APSGN patients found out the male suffered APSGN (60.5\%) more than female (39.5\%) with a ratio of 1.5: 1. The same result, in previous studies conducted in the Ethiopian by Mossie and Shimelis, they got $40(58.8 \%)$ male patients from 68 of APSGN cases. ${ }^{[13]}$

The relations of APSGN occurs in children by age group obtained a very significant difference with $\mathrm{p}=0.000,35.42$ COR values with $95 \%$ CI (4.51 to 278.27 ). The youngest age suffer APSGN at the age of 4 years and 3 months and the oldest at the age of 15 years and 6 months with a mean age of patients was 9.95 years. In the multivariate analyses, the age remains a risk factor of APSGN with 14.36 AOR obtained with $95 \%$ CI (1.56 to 132.58), which means that children with $\geq 5$ years old treated by ANS has 14.36 times greater risk for APSGN experience than the child aged $<5$ years. The distribution aged $\geq 5$ years in line with the incident that the Streptococcus bacteria infection (pharyngitis and skin infections) in children of school age. ${ }^{[16]}$ Another study by Mossie and Shimelis, got the highest APSGN age group between 6-10 years (44.1\%) with an age range between 2.5 to 14 years and the average age of 7.5 years. $^{[13]}$

The relations of APSGN incident on the nutritional status of children based on the group obtained a very significant differences with $\mathrm{p}=0.000$; COR value of 6.77 with $95 \% \mathrm{CI}$ (3.14 to 14.61). Allegedly that well nutrition affects the increase in antibodies, the result in the antigen-antibody reaction is quite good, which ultimately can lead to APSGN. Malnutrition is a risk factor in children with APSGN. ${ }^{[7]}$ Different with our study, malnutritional status was not found in APSGN patients while the under nutrition status is obtained as many as 65 patients and well nutritional status are 21 patients. This may be related to the condition of anergy in under nutritional status that does not allow or only slightly antigen antibody reaction can be formed so as not to trigger the occurrence of APSGN.

The APSGN incident on child relationship based on socioeconomic status obtained very significant differences with $\mathrm{p}=0.000 ; \mathrm{COR}=17.94$ with a $95 \% \mathrm{CI}(7.45$ to 43.21$)$. The multivariate analyses obtained AOR 5.25 with $95 \%$ CI (1.66 to 16.58), which means that children with low socioeconomic status were treated with ANS had a 5.25 times greater risk of experiencing APSGN than in children with high socioeconomic status. Socioeconomic level is an important factor in the occurrence of APSGN. In developed countries with the high socio-economic standards, APSGN incidents tend to be decrease. ${ }^{[13]}$
The relations of APSGN occurrence in children by maternal education level obtained a very significant differences with $\mathrm{p}=0.000(\mathrm{p}<0.01) ; \mathrm{COR}=18.95$ with a $95 \% \mathrm{CI}(7.63$ to 47.11). Multivariate analyses obtained AOR 5.54 with $95 \%$ CI (1.75 to 17.59), which means that children with less levels of maternal education were treated with ANS had 5.54 times the risk for experiencing APSGN than children whose mothers are highly educated. Maternal's education level with regard to the level of consciousness to bring their children for treatment at the health care center where health service factor becomes a decisive factor in improving the health status of children. Djaja study results, explains that mothers with higher education levels will be much more to bring their children to health facilities for medical treatment, but mothers with low levels of education would prefer their children to go to the traditional healers or treat by their own self. ${ }^{[17]}$ Study on the relationship between the levels of parental education on the incidence of APSGN is still limited, previous study in Indonesia earned $82 \%$ of the 509 cases of patients whose are come from the families with less education levels. This is same with the results obtained in this study, which the frequency of APSGN occurs more in children with less levels of maternal education (89.3\%) than in children with the high levels of maternal education $(30.6 \%)$.

The relationship between the season with the APSGN occurrence obtained a very significant differences with $\mathrm{p}=$ $0.003(\mathrm{p}<0.01)$. COR value $=2.91$ with $95 \%$ CI $(1.41$ to 5.99). Children who experience APSGN during the rainy season as many as $72.1 \%$ (62 children), while children with APSGN in the dry season as many as $47.1 \%$ (24 children). After the statistical test was done with the multivariate analyses, the rainy season remains a risk factor of APSGN AOR of 3.05 with $95 \%$ CI (1.11 to 8.36), which means that children treated with ANS had 3.05 times the risk of the APSGN occurrence in rainy season than in the dry season. This result might be due to the incidence of respiratory tract infections (tonsilofaringitis) and skin infections (pyoderma) which precedes APSGN incidence increased during the rainy season. This is in line with the study by Sepahi et al. who received 81 patients $(86.1 \%)$ of 87 APSGN patients occur during the rainy season (November to April). ${ }^{[1]}$

When all the four variables such as age $\geq 5$ year, low economy status, less of maternal education level, and rainy season put into the logistic regretion equation as an independence risk factor related to APSGN incidence on children treated with ANS, we got the percentage of $95.34 \%$. This means that if a children with ANS had all of those four risk factors, then the probability of having APSGN is $95.34 \%$. While the children with no risk factors only have the probability of having APSGN about $1.58 \%$.

In this study we uses a multivariate analyses and strict operational definition; therefore, the risk factors gained strongly as an independent factor. Moreover, in this study the APSGN risk factors can be seen easily from the history so it is very helpful for early diagnosis and management of further APSGN, particularly in areas with the minimal support facilities. Limitations of this study are solely using the existing data from the medical records that found some shortcomings in the data that is incomplete or not in 


\section{International Journal of Science and Research (IJSR) \\ ISSN (Online): 2319-7064 \\ Index Copernicus Value (2013): 6.14 | Impact Factor (2014): 5.611}

accordance with our necessary. In addition, this study used cross sectional design which ideally using a cohort design.

\section{Conclusion}

Based on the results of the study, we concluded that the risk factors of APSGN in children who show symptoms of ANS are $\geq 5$ years of age, low socioeconomic status, less maternal education level and the rainy season.

\section{Future scope}

It is necessary to conduct a multicenter cohort study for further study. It is also important to do a sosialization or parenting seminary on preventing and decrease the diseases cases with the family with less education levels.

\section{References}

[1] Madaio MP., Harrington JT. The diagnosis of glomerular diseases: acute glomerulonephritis and the nephrotic syndrome. Arch Intern Med. 2001; 161 (1): 25-34.

[2] Wong W. Glomerulonephritis-acute. Starship Children's Health Clinical Guideline. 2009; 1-3

[3] Takeno S., Wisanuyotin S., Jiravuttipong A. Risk factors and outcome of atypical acute post-streptococcal glomerulonephritis in pediatrics. Southeast Asian J Trop Med Public Health. 2013; (44) :2

[4] Carapetis Jonathan R., Andrew C Steer., E Kim Mulholland., Martin Weber. The global burden of group A streptococcal diseases. Lancet Infect Dis. 2005; 5: 685-94.

[5] Albar H., Rauf S. The profile of acute glomerulonephritis among Indonesian children. Paediatrica Indonesiana. 2005; 45 (11-12): 264-9.

[6] Pardede SO. Streptococcal Cell Structure and Pathogenesis of Acute Post Streptococcal Glomerulonephritis. Sari Pediatri. 2009; (11): 1: 58-63.

[7] Smith J., Faizan M., Eddy A. The child with acute nephritic syndrome. Clinical Pediatric Nephrology. $3^{\text {rd }}$ Edition. Oxford : Oxford University Press. 2003; 36679.

[8] Ho CZ., Chen YH. The clinical analysis of acute glomerulonephritis and nephrotic syndrome in Chinese children. J Med Sci. 1995; 15 (6): 429-40.

[9] Kumar G. Clinical study of post streptococcal glomerulonephritis in children with special reference to presentation. Curr Pediatr Res. 2011; 15 (2): 89-92.

[10]Ahn S., Ingulli E. Acute poststreptococcal glomerulonephritis: an update. Current Opinion in Pediatrics. 2008; 20: 157-62.

[11]Chiu CY, Huang YC, Wong KS. Poststreptococcal glomerulonephritis with pulmonary edema presenting as respiratory distress. Pediatr Nephrol. 2004; 19:12371240.

[12]Bircan Z., Tugay S., Usluer H. Poststreptococcal glomerulonephritis with pulmonary edema and microscopic hematuria. Pediatr Nephrol. 2005; 20: 1204.

[13] Mossie L., Shimelis D. Outcome of children with acute post streptococcal glomerulonephritis in Tikur Anbessa specialized teaching hospital. Ethiopian Journal of Pediatrics and Child Health. 2012; 8: 1-16.

[14] Derakhshan A., Hekmat VR. Acute glomerulonephritis in Southern Iran. Iran J Pediatr. 2008; 18 (2): 143-8.

[15] Sepahi MA., Shajari A., Shakiba M. Acute glomerulonephritis: a 7 years follow up of children in Center of Iran. Acta Medica Iranica. 2011; 49 (6): 375 8.

[16] Hassan R. Pediatrics Lecture books 2. Part of Pediatrics Faculty of Medicine, University of Indonesia. Infomedika Jakarta. 1985; 734-52.

[17]Djaja. Determinant of health seeking behavior in infants. Health Research Bulletin. 2001; 29-1. 